Assessing reintroduction schemes by comparing genetic diversity of reintroduced and source populations: A case study of the globally threatened large blue butterfly (Maculinea anion)

Andersen, Anne; Simcox, David J.; Thomas, Jeremy A.; Nash, David Richard

Published in:

Biological Conservation

DOI:

10.1016/j.biocon.2014.04.009

Publication date:

2014

Document version

Publisher's PDF, also known as Version of record

Citation for published version (APA):

Andersen, A., Simcox, D. J., Thomas, J. A., \& Nash, D. R. (2014). Assessing reintroduction schemes by comparing genetic diversity of reintroduced and source populations: A case study of the globally threatened large blue butterfly (Maculinea anion). Biological Conservation, 175, 34-41.

https://doi.org/10.1016/j.biocon.2014.04.009 


\title{
Assessing reintroduction schemes by comparing genetic diversity of reintroduced and source populations: A case study of the globally threatened large blue butterfly (Maculinea arion)
}

\author{
Anne Andersen $^{\mathrm{a}, *}$, David J. Simcox ${ }^{\mathrm{b}, \mathrm{c}}$, Jeremy A. Thomas ${ }^{\mathrm{b}, \mathrm{c}}$, David R. Nash ${ }^{\mathrm{a}}$ \\ ${ }^{a}$ Centre for Social Evolution, Section for Ecology and Evolution, Department of Biology, University of Copenhagen, Universitetsparken 15, 2100 Copenhagen, Denmark \\ ${ }^{\mathrm{b}}$ Department of Zoology, University of Oxford, South Parks Road, Oxford OX1 3PS, UK \\ ${ }^{\mathrm{C}}$ Centre for Ecology and Hydrology, Maclean Building, Benson Lane, Crowmarsh Gifford, Wallingford, Oxfordshire OX10 8BB, UK
}

\section{A R T I C L E I N F O}

\section{Article history:}

Received 20 July 2013

Received in revised form 2 April 2014

Accepted 7 April 2014

\section{Keywords:}

Conservation genetics

Effective population size

Founder effects

Bottlenecks

Species reintroduction

\begin{abstract}
A B S T R A C T
An important factor in reintroductions is the amount of genetic diversity captured in the introduced individuals. Introduced populations are initially small, and thus vulnerable to genetic drift and stochastic events. The level of genetic diversity maintained is important for the long-term persistence of populations and their evolutionary potential to react to, for example, climate changes. The national extinction of many butterfly species has been pronounced in many European countries. The globally Vulnerable large blue butterfly (Maculinea arion) went extinct in the UK in 1979 and was later reintroduced from Öland in Sweden. We investigated the genetic diversity of reintroduced large blues nineteen generations after translocation on five sites in the UK, and seven sites on Öland, including the source population. We found similar levels of genetic diversity in the reintroduced and source populations, but the UK and Swedish populations were genetically differentiated; we also found significant genetic differentiation among reintroduced UK populations only a few kilometres apart. The reintroduced populations had several private alleles not found in the source population in 2011 , and thus may already represent a unique subset of genetic diversity of the north-western populations of $M$. arion. Our results show that the IUCN and other protocols followed in the 1990s for translocating and maintaining the maximum available genetic diversity during reintroductions were largely adequate for this species, and hence will be valuable for informing the growing use of reintroductions as a strategy for the conservation of endangered species of insect.
\end{abstract}

(c) 2014 Elsevier Ltd. All rights reserved.

\section{Introduction}

Butterfly populations are declining worldwide due largely to the loss, degradation and fragmentation of their habitats (van Swaay and Warren, 2006). They also respond quickly in abundance (Roy et al., 2001), community structure (Devictor et al., 2012) and phenology to changes in climate (Diamond et al., 2011). Within Europe, the rates of decline of butterflies (Thomas et al., 2004), and other insect groups (Thomas, 2005; Conrad et al., 2006), have exceeded those of breeding birds and native vascular plants by an order of magnitude at national scales in recent decades, whilst across the Continent $12 \%$ of all butterfly species are threatened, more than half of which are associated with grasslands (van

\footnotetext{
* Corresponding author. Tel.: +45 50574011.

E-mail address: anne.andersen@outlook.dk (A. Andersen).
}

Swaay et al., 2010). Due to their high visibility and sensitivity to change, butterflies are increasingly used as bioindicators for identifying ecological trends; moreover, their conservation also protects endangered habitats and communities (Pe'er and Settele, 2008).

In response, the targeted conservation of single species or assemblages of butterflies has burgeoned in recent years, and increasingly includes the translocation or reintroduction of threatened species to new or former sites (Thomas et al., 2011a; Merckx et al., 2013). Unfortunately, very few of the earlier introductions succeeded (Oates and Warren, 1990), probably because the large majority of practitioners failed to follow recommended protocols concerning prior ecological knowledge and feasibility tests of the quality of habitat into which butterflies were released, and even fewer heeded IUCN (1995) and other guidelines (e.g. Soulé, 1987; Barker, 1994) to release $>60$ individuals sourced from large heterogeneous populations in order to maintain as much 
genetic diversity as possible, thus retaining the evolutionary potential of the reintroduced populations (Joyce and Pullin, 2003).

Butterflies that interact with ants (myrmecophiles) are among the most challenging to conserve successfully (Settele and Kühn, 2009), particularly those, as in the genus Maculinea (large blues), that live as obligate social parasites (Thomas and Settele, 2004). Nevertheless, many successful conservation projects, including the reintroduction of Maculinea arion $\mathrm{L}$. to the UK (Thomas et al., 2009) and Maculinea nausithous Bergstr. and Maculinea teleius Bergstr. to The Netherlands (Wynhoff et al., 2001), have occurred since Maculinea were chosen by the IUCN in the 1980s as one of three global priorities for Lepidoptera conservation (Thomas and Settele, 2004; Settele et al., 2005).

The reintroduction of $M$. arion to the U.K., following its extinction in 1979 due to habitat degradation (Thomas, 1980), is the longest running, largest scale project involving Maculinea to date, and has been one of the major success stories of insect conservation (Thomas et al., 2009). M. arion is primarily a social parasite of the ant Myrmica sabuleti Meinert, and is further dependent on the flowers of Thymus spp. L. or Origanum vulgare L. as early larval food plants (Thomas, 1980). In the years following its disappearance from the UK, around fifty former sites were restored as Thymus grassland with large populations of M. sabuleti. M. arion was reintroduced from 1983 to 1992, using source individuals from sites on the Stora Alvaret, Öland, Sweden (Fig. 1; Thomas et al., 2009). The Öland race was chosen out of several European populations tested for its physiological similarity to the extinct UK populations, and because Öland supported the largest known surviving northern populations (Thomas et al., 2009) of this (then) globally Vulnerable species ( $M$. arion was upgraded to Endangered in the 1994 IUCN Red List of threatened species before downgrading, as conservation measures succeeded, to its current status of Near
Threatened: it remains an Endangered Species in Europe; Thomas et al., 2011b). Although the reintroduction has been successful in terms of re-establishing the large blue in Britain in increasing and predictable numbers (Thomas et al., 2009), for its long-term viability it is vital that adequate genetic diversity is represented (Joyce and Pullin, 2003). The standard advice (above) for maintaining genetic diversity at the time (1983-92) was followed during the translocations: on each occasion $>250$ larvae were collected from separate flower heads (to maximize the chance that they were offspring of different mothers) from 11 demographically distinct populations separated by up to $10 \mathrm{~km}$ on the Stora Alvaret (all part of Öland 2; Fig. 1) for release on each UK introduction site. However, no genetic analysis of the source population or the introduced individuals was carried out before the reintroductions, and recent studies have shown that effective population sizes (the number of breeding individuals in an ideal population that would show the same level of genetic drift as that observed in the sampled population; Wright, 1938) of Swedish M. arion are small (Ugelvig et al., 2012).

In the Polden Hills, Somerset (UK), where the species was reintroduced to a single site (Poldens 1; Fig. 1) in 1992, it now occupies around 25 sites, of which at least 22 represent natural colonizations and three were further translocations from Poldens 1 and 3 (Thomas et al., 2009). Under UK climates, the reintroduced $M$. arion population emerged 2-3 weeks earlier than on Öland, coinciding with the phenologies of the extinct populations and local Thymus flower bud production (Thomas et al., 1998, 2009), and has since converged ever closer (Thomas et al., 2011b). Moreover, the rate of colonization of new sites has increased during the second decade after reintroduction as vacant patches across the Polden Hills landscape were filled by mainly stepping stone colonizations from neighboring sites (Thomas, 2010), suggesting selection for

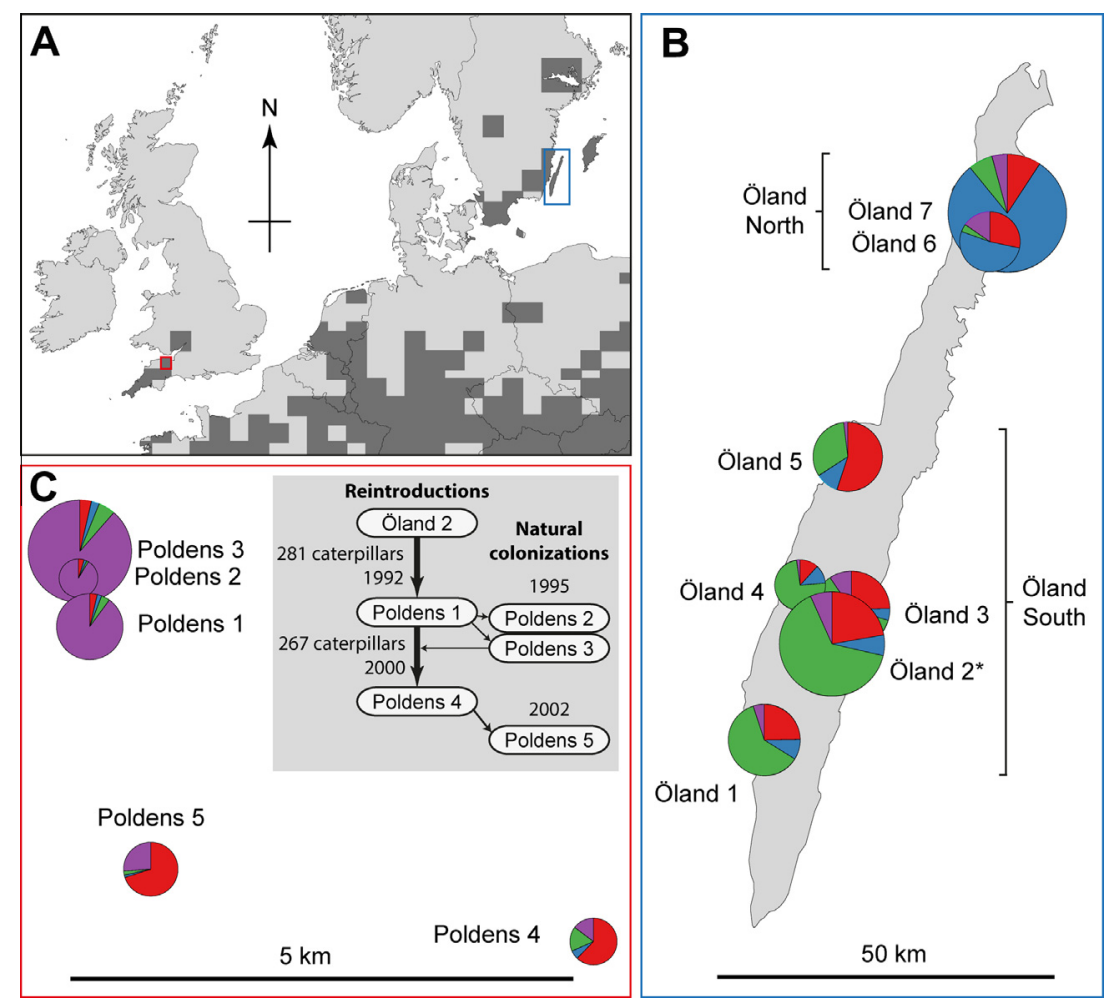

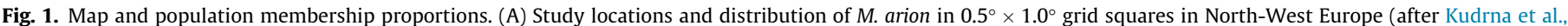

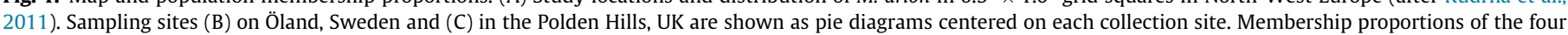

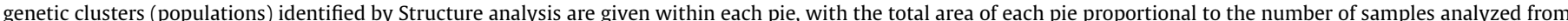

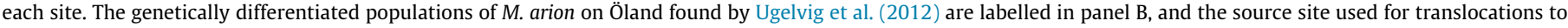
the UK (Öland 2) is marked with an asterisk. The inset in panel C summarizes the reintroduction and colonization history of the five UK sites. 
increasingly dispersive individuals, as is typical for expanding populations (Phillips et al., 2010), and has been inferred for 19th century expansions of UK M. arion populations (Dempster, 1991).

To our knowledge, no genetic comparison with the source has previously been made of an apparently successful introduction to the wild of an insect species as long as 19 generations after its reintroduction, although M. nausithous and M. teleius were studied five generations after release (Wynhoff et al., 2001). We used fourteen microsatellite markers to examine the genetic diversity of a subset of the reintroduced $M$. arion populations, and compared this with populations on Öland. To evaluate the reintroduced population's evolutionary potential we ask: (1) Was the level of genetic diversity preserved during the reintroduction and 19 subsequent generations in the UK? (2) Is the reintroduced population genetically differentiated from the source population due to founder effects? and (3) Does the differentiation of populations following reintroduction reflect their known histories?

\section{Methods}

\subsection{Sampling}

The collection methods used in the UK and Sweden were tailored to our knowledge of the different populations. The UK sites are geographically small, and eggs counts are made annually, so that caterpillars could be collected relatively easily. Sites on Öland were more extensive, and details of oviposition sites were not available, so that non-destructive collection of adult material was deemed to be most suitable. Both sampling techniques have been used previously (Ugelvig et al., 2011; Zeisset et al., 2005), and amplify identical alleles (unpublished data).

UK. A total of $59 \mathrm{M}$. arion caterpillars were collected on five sites (Poldens 1-5) in the Poldens Hills in July 2011, from a few hundred metres to nearly seven kilometres apart (Fig. 1c). Sampling was restricted to the five largest UK populations, and even then some sample sizes were limited, due to the problems associated with sampling from small subpopulations of a UK and European Endangered Species. Caterpillars were collected from food plants across sites, and were of variable age and therefore likely to be the progeny of multiple females. This sampling scheme was chosen due to the relative ease of extracting DNA from caterpillars, and the assessment that the sampling would have negligible impact on the populations, since later larval mortality is high (>85\%) and density dependent compared with other life stages in Maculinea in populations that have reached site carrying capacities (Als et al., 2001; Thomas et al., 2009). Coordinates were approximated from sampling location maps using the program MapSource 6.16.3 (Garmin Ltd.).

Sweden. DNA samples from $128 \mathrm{M}$. arion were collected in July 2010-11 on seven sites across Öland, covering approximately $80 \mathrm{~km}$ (Fig. 1b), and including the source area for the translocation to the UK (Öland 2). Samples were collected using a non-destructive sampling method, removing $2-3 \mathrm{~mm}^{2}$ of the edge of one hind wing. This type of wing damage is very similar to that caused by bird attack (Lushai et al., 2000), and has no negative effect on the flight ability of the butterflies (Hamm et al., 2010) or on long-term survival (Koscinski et al., 2011). The coordinates of each catch location were recorded using a handheld GPS receiver (Garmin eTrex Vista, accuracy $\pm 5 \mathrm{~m}$ ).

\subsection{DNA extraction, amplification and basic characterization of microsatellite loci}

DNA was extracted from wing fragments or $1 \mathrm{~mm}$ of caterpillar tissue using $100 \mu \mathrm{l}$ \% Chelex-TRIS $(10 \mathrm{mM}$ ) and $5 \mu$ l proteinase $\mathrm{K}$
( 0.75 units) per sample. The wing fragments were incubated at $56{ }^{\circ} \mathrm{C}$ for $3.5 \mathrm{~h}$ and all samples were boiled at $99{ }^{\circ} \mathrm{C}$ for $15 \mathrm{~min}$ and centrifuged at $13,000 \mathrm{~g}$ for $3 \mathrm{~min}$. The supernatant was stored at $-20^{\circ} \mathrm{C}$.

Fourteen polymorphic nuclear microsatellite loci were amplified for all 187 samples. Primers were developed for M. arion or closely related Maculinea-species and are published in Ugelvig et al. (2011, 2012) and Zeisset et al. (2005) (see Table A1). Polymerase chain reaction (PCR) conditions were as follows: initial denaturation $95^{\circ} \mathrm{C}$ for $5 \mathrm{~min}$, followed by 40 cycles of $95^{\circ} \mathrm{C}$ for $30 \mathrm{~s}$, $56 / 57 / 62{ }^{\circ} \mathrm{C}$ for $30 \mathrm{~s}, 72{ }^{\circ} \mathrm{C}$ for $30 \mathrm{~s}$ and annealing at $56 / 57 / 62{ }^{\circ} \mathrm{C}$ for $1 \mathrm{~min}$. The run was completed by a final annealing at $72^{\circ} \mathrm{C}$ for $60 \mathrm{~min}$. Total reaction volume was $12.5 \mu \mathrm{l}$ whereof $1 \mu \mathrm{l}$ was DNA extract. PCR products were run with a Gene-scan-500 LIZ size standard on an ABI 3130 automated sequencer and results were analyzed with Genemapper 4.0 (both Applied Biosystems).

Each microsatellite locus was analyzed separately for departure from Hardy-Weinberg Equilibrium using Genepop 4.0 (Rousset, 2008). Genepop was also used to test for linkage disequilibrium between pairs of loci as it may affect F-statistics (see below). Departures from Hardy-Weinberg equilibrium across loci can be due to inbreeding or population substructure (Wallace, 1981), while single locus departure might be an indication of the presence of null alleles (for which DNA sequences do not amplify because of changes in the primer region; Chapuis and Estoup, 2007). The data were tested for the presence of null alleles using Micro-Checker 2.2.3 (van Oosterhout et al., 2004). Null alleles may be present at loci Macari23 (maximum frequency 0.24) and Macari08 (0.21) in the UK samples, and in Macu44 (0.09), Macari16 (0.11), Macari18 (0.12) and Macari23 (0.25) in the Öland samples. Null alleles may affect F-statistics, but the bias introduced is negligible if they are present at low frequencies ( $<0.20$; Dakin and Avise, 2004). For that reason allele frequencies were not adjusted, but Macari23 was removed from further analysis.

\subsection{Genetic distances}

The genetic relationships among sampling sites were analyzed by calculation of pairwise genetic differentiation $\left(F_{\mathrm{ST}}\right)$ among all sites, and among three regions identified based on Ugelvig et al. (2012) i.e. UK, Öland South and Öland North (Fig. 1) using Fstat 2.9.3.2 (Goudet, 1995). We also conducted hierarchical analysis of molecular variance (AMOVA) within and between sites for the UK samples, and within sites, among sites and among regions for the entire dataset using 9999 permutations in GenAlEx 6.501 (Peakall and Smouse, 2012).

\subsection{Spatial genetic structure}

Species' geographical distributions are in general more extensive than the dispersal capacity of an individual, leading to spatial population genetic structure (Rousset, 1997). Mantel tests (Mantel, 1967) were performed to assess Isolation-By-Distance within the reintroduced and Öland populations. Genetic distances between populations (measured as $F_{\mathrm{ST}} /\left(1-F_{\mathrm{ST}}\right)$ ) are predicted to increase approximately linearly with the logarithm of the geographical distance between sites (Rousset, 1997). Geographical distances were calculated in SPAGeDi 1.3 (Hardy and Vekemans, 2002) and Mantel tests were performed in GenAlEx 6.501 using 999 permutations.

The population structures of the reintroduced and Öland samples were investigated to detect the presence of population boundaries among the sampled individuals by assigning individuals to genetic clusters (populations). The number of populations, $K$, was modeled using the Bayesian clustering approach implemented in Structure 2.3.4 (Falush et al., 2003; Hubisz et al., 2009; Pritchard et al., 2000) using admixture ancestry models with correlated 
allele frequencies, with and without sampling location as prior information (Hubisz et al., 2009), and with a burn-in of $10^{4}$ and $10^{6}$ Markov chain Monte Carlo (MCMC) generations, for 10 replicate runs of $K=2-12$. The model was run on the total dataset (UK and Öland) and on ten different random subsamples of four individuals (the lowest number sampled from any single site) from each sampling site. The latter analysis was performed to test whether the results were sensitive to uneven sampling and small sample sizes. Evaluation of the likelihood values of $K$ and detection of the number of populations followed the methods of Evanno et al. (2005) implemented in the web-based Structure Harvester v0.6.93 (Earl and von Holdt, 2012).

\subsection{Demographic histories}

Population bottlenecks can reduce genetic variation, fix deleterious alleles and cause inbreeding depression, and thus reduce the evolutionary potential of populations (Frankham, 2005). We tested for recent population bottlenecks using the $M$-ratio method introduced by Garza and Williamson (2001), who demonstrated how the ratio of the number of alleles to range in allele size for a sample of microsatellite loci can be used to detect reductions in effective population size. Parameter values followed those recommended by the authors with a single exception: the fraction of mutations that are larger than single steps was set to $p_{s}=0.2$, double the originally recommended value, following Peery et al. (2012). $M$-ratio is sensitive to sample size and small sample sizes can lead to bias (Garza and Williamson, 2001), so only populations with more than 25 sampled individuals were analyzed (i.e. the UK (Poldens 1-3 combined), Öland South and Öland North). Critical values of the $M$-ratio were calculated for values of $\theta$ (defined as $4 N_{e} \mu$, where $N_{e}$ is the effective population size, and $\mu$ is the microsatellite mutation rate) ranging from 0.002 to 40 , reflecting uncertainty in long-term equilibrium population sizes. Effective population sizes for the different populations were also estimated from the sample data using the web-based program ONeSAMP 1.2 (Tallmon et al., 2008). Allele loss through stepping-stone reintroduction was tested using nested subset analysis (Habel et al., 2013) implemented in the "vegan" package (v. 2.0-7; http://cran.rproject.org/web/packages/vegan/) for R (v.3.0.1; R-project).

\subsection{Genetic diversity statistics}

The percentage of polymorphic loci $(\mathrm{P})$, allelic richness $(k)$, expected heterozygosity $\left(\mathrm{H}_{\mathrm{e}}\right)$ and the inbreeding coefficient $\left(F_{\mathrm{IS}}\right)$ of each population were calculated in GenAlEx and Fstat. P, $k$ and He were used as estimates of genetic diversity. The frequency and identity of private and shared alleles of each population were analyzed in GenAlEx. Levels of genetic diversity among populations and $F_{I S}$-values were compared using ANOVA in $\mathrm{R}$ (v.3.0.1; R-project).

\subsection{Genetic differentiation}

Genetic drift, mutation and natural selection can all lead to genetic differentiation among populations. The indices $F_{\mathrm{ST}}$ and $R_{\mathrm{ST}}$ both describe the degree of genetic differentiation among populations, based on the infinite alleles and stepwise models for microsatellite mutation respectively (Phillippe and Lagoda, 1996). The comparison of the two indices can shed light on the main causes of population differentiation. If differentiation is driven mainly by drift, the two are expected to be approximately equal. If stepwise-mutations contribute to differentiation, however, $R_{\mathrm{ST}}$ is expected to be larger than $F_{\mathrm{ST}}$ (Hardy et al., 2003). $F_{\mathrm{ST}}, R_{\mathrm{ST}}$ and $p R_{\mathrm{ST}}$ (the $95 \%$ confidence limit on $R_{\mathrm{ST}}$ based on 1000 allele-size randomizations) among the UK populations and between the combined UK and Öland populations were computed in SPAGeDi 1.3 (Hardy and Vekemans, 2002). If $R_{\mathrm{ST}}$ is significantly greater than zero and greater than $p R_{\mathrm{ST}}$, then stepwise-like mutations contribute to population differentiation for at least one locus.

\section{Results}

Three loci, Macu9, Macu17 and Macu15, were not in HardyWeinberg equilibrium in Öland South, Öland North and the combined UK population, respectively. All other loci were in equilibrium in all populations. Linkage disequilibrium between pairs of loci was detected in Macu $8 \times$ Macari19 (only in Öland South) and Macu9 $\times$ Macari18 (in the two Öland populations). These moderate deviations from local panmixis were not expected to affect the results of any of the analyses, so all loci except the previously discarded Macari23 (see Section 2) were retained.

\subsection{Number of populations and genetic differentiation}

Bayesian population assignment analysis using Structure showed strongest support for four populations (genetic clusters) among the sampled $M$. arion individuals. This result was consistent with and without a location prior, showing that the signal of population structure is relatively strong (Hubisz et al., 2009). The four clusters consisted of individuals collected: in southern Öland (Öland South), in northern Öland (Öland North), at Poldens 1-3 (UK1) and at Poldens 4-5 (UK2) (Fig. 2). 80\% and 60\% of all individuals could be assigned to a single cluster with a probability $>80 \%$ with and without a location prior, respectively, showing that there was little or no admixture between clusters. The ten random subsample runs showed largest support for three or four clusters (Fig. A1). The three genetic clusters detected corresponded to Öland South, UK1 and either Öland North or UK2. For $K=4$, the four clusters corresponded with the four clusters detected in the full dataset (Fig. A1). The division of the reintroduced sites into two populations was also supported by pairwise $F_{\mathrm{ST}}$-values, suggest that the Poldens 4 and Poldens 5 sites are significantly genetically differentiated from the other sites (Table A2). The calculated pairwise $F_{\mathrm{ST}}$-values between the regions were all significantly greater than zero, and suggest that the UK populations are genetically differentiated from both Öland South $\left(F_{\mathrm{ST}}=0.0554\right)$, and Öland North $\left(F_{\mathrm{ST}}=0.0626\right)$. In comparison, $F_{\mathrm{ST}}=0.0362$ between the two Öland populations. $89 \%$ of the molecular variance in the UK populations was within sites while $11 \%$ was distributed among sites. For the combined data set, $88 \%, 6 \%$ and $6 \%$ of the molecular variance was explained within sites, among sites and among regions (i.e. UK, Öland South and Öland North), respectively. The UK populations showed low, but significant Isolation-by-Distance $(r=0.795$, slope $=0.011, p=0.043)$, as did the Öland source population $(r=0.817$, slope $=0.001, p=0.025)$, indicating limited dispersal ability of $M$. arion. $R_{\mathrm{ST}}$ between the UK sites was 0.123 , which was significantly higher than $F_{\mathrm{ST}}(0.0590, p=0.047)$. Hence, stepwise-like mutations may have contributed to the genetic differentiation among the UK populations (Hardy et al., 2003). $R_{\mathrm{ST}}(0.0847)$ between the UK and Öland populations was also significantly higher than $\mathrm{F}_{\mathrm{ST}}(0.0495, p=0.041)$.

\subsection{Demographic histories}

The $M$-ratio for the UK population (0.559) was far below critical values (0.638-0.796 for theta $40-0.002)$, indicating a recent population size reduction. The $M$-ratios for the Öland South (0.621) and Öland North (0.606) populations were also lower than the critical values, and all were below the generally accepted cut-off value of $M=0.68$, under which it is reasonable to assume that a population 


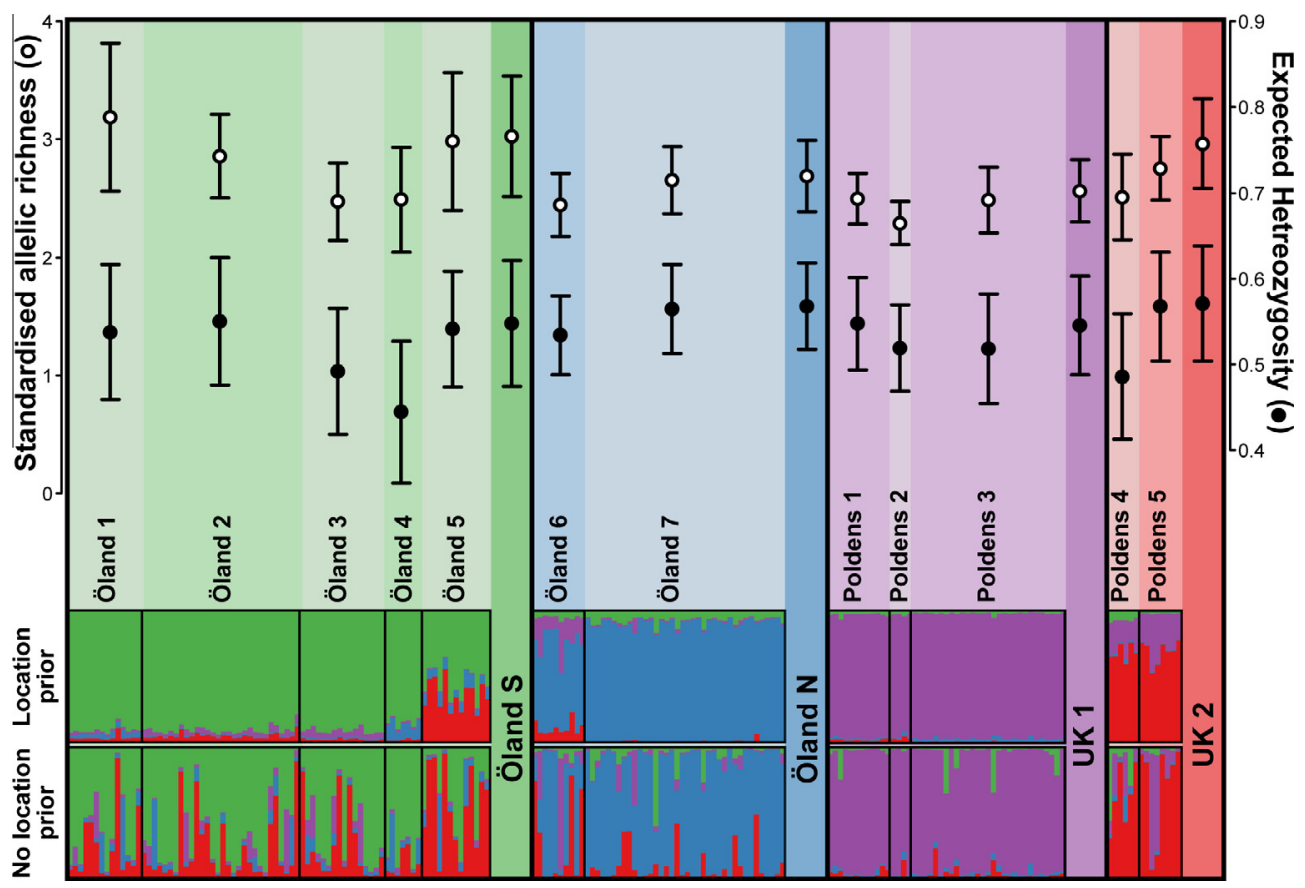

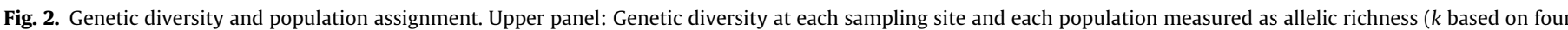

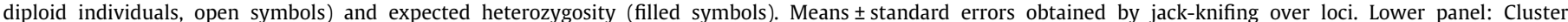

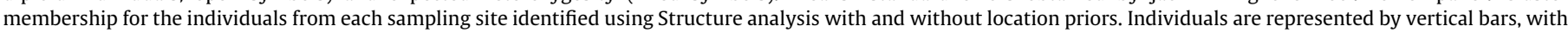

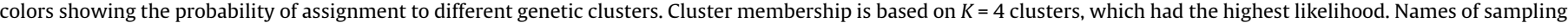
sites (see Fig. 1) are given above the membership diagram, and the populations to which they were assigned based on these clusters to the right of each panel.

analyzed for more than seven loci has recently experienced a population size reduction (Garza and Williamson, 2001). Estimated effective populations sizes for each population were small (mean [95\% confidence limits]; UK1: 25.3 [20.2-34.0]; UK2: 18.7 [15.9-25.5]; Öland north: 29.2 [23.6-41.5]; Öland south: 51.6 [39.4-78.5]), which also suggests either recent bottlenecks or continued restricted population sizes over several generations.

\subsection{Genetic diversity}

The level of genetic diversity was not significantly different among the reintroduced and source sites, regardless of which measure was used (Fig. 2). Although comparisons between studies using different microsatellite loci can be problematic, the mean expected heterozygosity for each of the populations (0.45-0.57) was low compared to some $M$. arion populations in Poland (0.61-0.74: Rutkowski et al., 2009; 0.52-0.81: Sielezniew and Rutkowski, 2012), but of similar levels to other studies from Scandinavia (0.38-0.67: Ugelvig et al., 2012). Locus Macari18 was monomorphic in the UK populations, and Macari16 was monomorphic in Öland South. All other loci were polymorphic in all populations. $F_{\mathrm{IS}}$-values were not significantly different from zero $\left(F_{11,156}=1.23, p=0.26\right)$, showing no evidence of non-random mating within sites. Comparing the known reintroductions (from Öland 2 to Poldens1, and Poldens $1 / 3$ to Poldens 4), there was no sign of reduced genetic diversity in the translocated populations, or any step-wise loss of alleles (nested subset analysis, $\mathrm{NDOF}=66.74, p=0.73$ ). Nine alleles were present only in the UK (private alleles for this region), of which six were present only in one or other population (Fig. 3). In comparison the Öland South and Öland North populations had seventeen and three private alleles, respectively. Several alleles were also shared by the UK and Öland North populations, but not the Öland south population (Fig. 3).

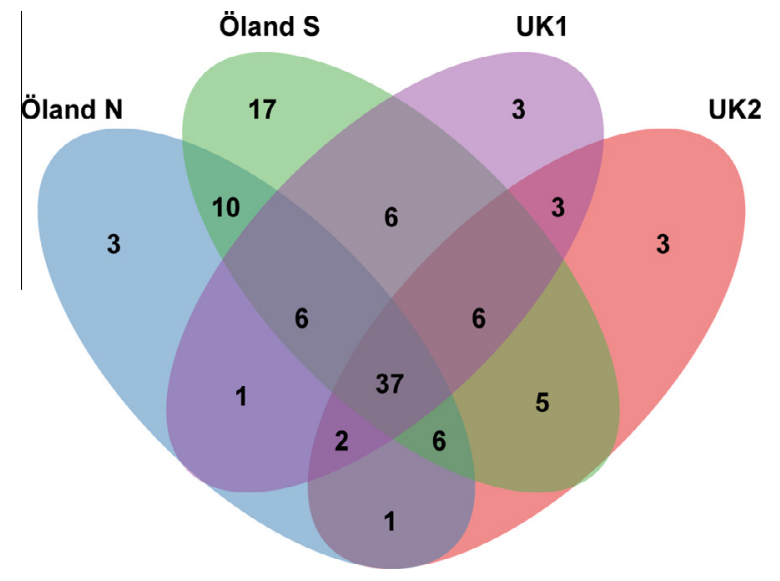

Fig. 3. The distribution of the total number of microsatellite alleles within and between the four populations identified using Structure.

\section{Discussion}

The reintroduced UK populations had similar levels of genetic diversity to the source population and to other populations in Scandinavia, suggesting that the standard recommendations at the time - and indeed current advice (IUCN, 2013) - for maintaining genetic diversity during conservation translocations was effective for M. arion. However, this similarity in genetic diversity was also surprising, considering the known reintroduction and stepping stone colonization history of $M$. arion in the UK. Species with stepping stone dispersal are expected to experience successive losses of genetic variation (e.g. Besold et al., 2008), which suggests that other processes may be involved in the equalization of genetic diversity in this case. 
While the levels of genetic diversity have not changed significantly, the allele frequencies among the UK populations have. The reintroduction site and the two sites closest to it (Fig. 2) represented a single genetic population. The other two sites, Poldens 4 and Poldens 5, were significantly differentiated from the Poldens 1-3 cluster, but not from each other. The genetic clustering of ten different random subsamples suggests that this is not an artefact of different sample sizes (Fig. A1). The pattern of genetic differentiation among sites, but no detectable inbreeding within sites, suggests low levels of gene flow, but high local population densities. The quality of the larval habitat is critical for butterfly populations, and the correlation between larval habitat quality and butterfly density is close for $M$. arion $\left(r^{2}=0.99\right.$; Thomas et al., 2011). No studied site in Europe has as near a high co-occurrence of food plant and M. sabuleti ranges as the restored UK sites (Thomas et al., 2009). Restoration and targeted management of the UK sites for $M$. arion has increased its carrying capacity at the most successful sites (e.g. Poldens 1 and 4, Fig. A2) to levels that are considerably higher than those observed elsewhere. Indeed UK sites currently support the highest known densities of $M$. arion in the world (Thomas et al., 2009).

The individuals reintroduced to Poldens 1 in 1992 collected on Öland were from 11 sites representing a subset of one large genetic source population (Öland South). The Poldens 1 population was expected to have experienced founder effects (i.e. change in allele frequencies) during the reintroduction event. Moreover, founding populations experience different selection pressures in their new environment. Eggs and larvae collected on Öland were reared to their final larval instar before they were released on Poldens 1 at low densities. A total of 281 caterpillars were introduced to the site (Thomas et al., 2009) and due to the optimal habitat conditions on the site, caterpillar survival was unusually high. The population at the Poldens 1 site has also dramatically increased in numbers, and is connected by gene flow to neighboring sites, forming a single population (UK1). The population on Poldens 4 was introduced in the year 2000 using 267 caterpillars from the Poldens 1 and 3 sites, and is thus expected to be a genetic subset of that population. Poldens 4 declined to $\approx 35$ adult females in 2001 and at least $40 \%$ of those females failed to live long enough to lay eggs, which could account for the genetic differentiation from its source population, via strong genetic drift, but not for the presence of private alleles. We believe that the Poldens 5 population was founded by natural colonization, first recorded in 2002 (Hamish Cole, pers. comm.). The genetic similarity of Poldens 5 to Poldens 4 is unexpected, as Poldens $1-3$ are closer and $\approx 20$ times larger, but colonization from Poldens 4 is also feasible. The number of founding females is unknown, but the smallest size it sustained in 2005-12 was 48 females. Thus it appears that the differentiation between populations in the UK and between the UK and Öland is associated with translocation events rather than natural colonizations, and that gene flow between naturally colonized sites is high.

The $M$-ratio for the UK populations was lower than for the Öland populations, as were estimated effective population sizes, but all populations had $M$-ratios below the critical values expected if they had not recently experienced a severe population bottleneck. Ugelvig et al. (2012) also found low M-ratios in other Swedish $M$. arion populations, suggesting that this might be a natural consequence of the extraordinary phyto-predacious lifestyle of $M$. arion where only a small, non-random, fraction of eggs survive to adulthood, so that typical populations have a very low effective population size and essentially experience bottlenecks in most generations. This is supported by the universally low effective population sizes estimated in this study. Low effective population sizes will expose $M$. arion to the effects of genetic drift, resulting in the observed rapid genetic differentiation of neighboring populations if gene flow is hindered (Bereczki et al., 2005) and high temporal turnover in allele frequencies within populations (Ugelvig et al., 2011). It also suggests that generations of low effective population sizes are likely to have been effective in purging deleterious alleles from M. arion (Ugelvig et al., 2011). The large discrepancy between observed population sizes (e.g. Poldens 1 has reached a carrying capacity in excess of 1000 breeding females; Fig. A2) and estimated effective population sizes (e.g. 23.5 for population UK1) is far greater than that expected on theoretical grounds for stable populations, and quite extreme for populations in the wild (Frankham, 1995). For the U.K. populations this may reflect the rapid expansion that they have undergone over the 19 generations since reintroduction, which is expected to lead to the observed pattern of low effective population size and strong differentiation between sites (Excoffier and Ray, 2008; Phillips et al., 2010). However, this cannot explain the low effective population sizes for samples from Öland, which again suggests that the extraordinary biology of $M$. arion leads to an unusual genetic structure, and that the similarity in genetic diversity across $M$. arion populations may be due to a phenology that leads to inherently low but constant genetic diversity.

A severe drought on Öland in 1992 left almost no flowering Thymus for $M$. arion oviposition, and the species was observed to shift to small habitat patches with taller turf and low densities of $M$. sabuleti, where it oviposited on 0 . vulgare (Elmquist and Nielsen, 2007; Simcox unpublished). Droughts also have serious negative effects on female longevity and natality, as well as reducing the tolerance of Myrmica ants to intruders (Thomas et al., 2009), and only two flying individuals were recorded on Öland the following year (Thomas et al., 2005b). The onset of drought coincided with the year of the collection of $M$. arion eggs and caterpillars for the reintroduction to Poldens 1 (Thomas et al., 2009). Thus, alleles lost from the Öland population during its 1992-93 bottleneck may have been preserved in the reintroduced populations in the UK. The presence of private alleles might otherwise be explained by mutations in the UK populations, or that we did not sample these alleles in the Öland-populations, despite their presence. The large sample size of the Öland-populations suggests that the latter explanation is unlikely, although we cannot exclude the possibility they were present at very low frequencies. This would have required a subsequent increased in frequency after introduction to the UK, perhaps through "gene surfing", where rare alleles can become common through genetic drift at the expansion front of a growing population (Excoffier and Ray, 2008). We did find evidence that step-wise mutations may contribute to the genetic differentiation among the UK populations, and between the UK and Öland populations. Examining the UK private alleles showed that indeed five out of nine private alleles represent one-step mutations, but the other four would require 2-7 steps. While this would suggest rather high mutation rates over just 19 generations, the large and rapidly expanding populations in the UK would be more likely to accumulate mutations in neutral markers than small, stable populations (Klopfstein et al., 2006).

The only other study comparing the genetics of reintroduced and source populations of Maculinea butterflies was carried out by Wynhoff et al. (2001) on M. nausithous and M. teleius reintroduced to the Netherlands from Polish source populations. Using allozymes, they also found strong differentiation between source and reintroduced populations after five generations, but the retention of similar levels of genetic diversity, despite relatively small numbers of translocated individuals (70 for M. nausithous and 86 for M. teleius). They also found one private allele (out of a total of 17 alleles at polymorphic loci) among the inherently less variable allozymes in the reintroduced population of $M$. nausithous, suggesting that similar mechanisms of genetic divergence may operate across all the predatory Maculinea butterflies (Als et al., 2004). 


\subsection{Conservation}

The reintroduction of $M$. arion to the UK has been extremely successful in terms of population persistence and natural colonization, and both observed population fluctuations and trends closely adhered to predictions of a population dynamic model parameterized from the former UK race (Thomas et al., 2009). The maintenance of similar levels of genetic diversity in the reintroduced population and populations on Öland suggest that this was a suitable choice as source population, and that the number of introduced individuals was sufficient to counteract loss of genetic variation caused by the reintroduction event. Furthermore, the restoration and management of the reintroduction site and the nearby habitat patches has ensured high initial population growth and generally large population sizes. The pattern of genetic diversity across populations also suggests that the extraordinary life cycle of $M$. arion, which leads to low effective population sizes but relatively large numbers of breeding individuals, may drive its population genetics. The genetic differentiation among the UK populations only a few kilometres from each other, as reported in this study, should be taken into account in the management of the population to ensure its evolutionary potential. The first step is to conduct further genetic studies of the intermediate unsampled sites to clarify whether neighboring populations are isolated or connected by gene flow as observed in the Öland South population.

\section{Conclusion}

The reintroduced UK populations seem to represent a unique subset of the genetic diversity of the northwestern populations of $M$. arion, despite their relatively recent origin from an extant population. This highlights the importance of reintroductions in species conservation to ensure overall genetic diversity. The genetic guidelines at the time of reintroduction (1983-92), and subsequently, have proven to be sufficient to preserve genetic diversity in the UK population. The populations have been observed to use alternative food plants and host ants in extreme years. This ability, combined with no loss of genetic diversity and lack of inbreeding in the populations, gives reason for cautious optimism that species in this iconic genus will be able to persist during future climate changes. More generally, the results are sufficiently encouraging to expect that, in contrast to the disappointments of earlier decades (Oates and Warren, 1990), reintroductions of other insect species are likely to succeed if IUCN guidelines are strictly followed, even if the populations in question, as here, are drawn from and are adapted to - sites near the edges of species' ranges, where genetic diversity is intrinsically low.

\section{Acknowledgements}

We thank A. Illum, L.V. Ugelvig and P.S. Nielsen for assistance with sampling in Sweden. In the UK, we thank Somerset Wildlife Trust, Network Rail, the National Trust and H. Cole for access to sites, and Natural England for a license to sample butterflies. In Sweden, collection was made possible through a permit from the Åtgärdsprogrammet, supported by the Swedish Environmental Protection Agency. This study was funded by the Danish National Research Foundation, via a grant to the Centre for Social Evolution, Department of Biology, University of Copenhagen (DNRF57). D.J.S. and J.A.T. thank the FP6 BiodivERsA Era-net project CLIMIT and the German FMER for funding.

\section{Appendix A. Supplementary material}

Supplementary data associated with this article can be found, in the online version, at http://dx.doi.org/10.1016/j.biocon.2014.04.009.

\section{References}

Als, T.D., Nash, D.R., Boomsma, J.J., 2001. Adoption of parasitic Maculinea alcon caterpillars (Lepidoptera : Lycaenidae) by three Myrmica ant species. Anim. Behav. 62, 99-106.

Als, T.D., Vila, R., Kandul, N., Nash, D.R., Yen, S.H., Hsu, Y., Mignault, A., Boomsma, J.J., Pierce, N.E., 2004. The evolution of alternative parasitic life histories in large blue butterflies. Nature 432, 386-390.

Barker, J.S.F., 1994. Animal breeding and conservation genetics. In: Loeschcke, V. Tomiuck, J., Jain, S.K. (Eds.), Conservation Genetics. Birkhäuser, Basel, pp. 381-398.

Bereczki, J., Pecsenye, K., Peregovits, L., Varga, Z., 2005. Pattern of genetic differentiation in the Maculinea alcon species group (Lepidoptera, Lycaenidae) in Central Europe. J. Zool. Syst. Evol. Res. 43, 157-165.

Besold, J., Schmitt, T., Tammaru, T., Cassel-Lundhagen, A., 2008. Strong genetic impoverishment from the centre of distribution in southern Europe to peripheral Baltic and isolated Scandinavian populations of the pearly heath butterfly. J. Biogeogr. 35, 2090-2101.

Chapuis, M.P., Estoup, A., 2007. Microsatellite null alleles and estimation of population differentiation. Mol. Biol. Evol. 24, 621-631.

Conrad, K.F., Warren, M.S., Fox, R., Parsons, M.S., Woiwod, I.P., 2006. Rapid declines of common, widespread British moths provide evidence of an insect biodiversity crisis. Biol. Conserv. 132, 279-291.

Dakin, E.E., Avise, J.C., 2004. Microsatellite null alleles in parentage analysis. Heredity 93, 504-509.

Dempster, J.P., 1991. Fragmentation isolation and mobility of insect populations. In: Collins, N.M., Thomas, J.A. (Eds.), The Conservation of Insects and Their Habitats. Academic Press, London, pp. 143-154.

Devictor, V., van Swaay, C., Brereton, T., Brotons, L., Chamberlain, D., Heliölä, J., Herrando, S., Julliard, R., Kuussaari, M., Lindström, Å., Reif, J., Roy, D.B., Schweiger, O., Settele, J., Stefanescu, C., Van Strien, A., Van Turnhout, C., Vermouzek, Z., WallisDeVries, M., Wynhoff, I., Jiguet, F., 2012. Differences in the climatic debts of birds and butterflies at a continental scale. Nat. Climate Change 2, 121-124.

Diamond, S.E., Frame, A.M., Martin, R.A., Buckley, L.B., 2011. Species’ traits predict phenological responses to climate change in butterflies. Ecology 92, 1005-1012.

Earl, D., von Holdt, B., 2012. Structure Harvester: a website and program for visualizing Structure output and implementing the Evanno method. Conserv. Genet. Res. 4, 359-361.

Elmquist, H., Nielsen, P.S., 2007. Åtgärdsprogram för bevarande av svartfläckig blåvinge (Maculinea arion). Rapport 5652. Naturvårdsverket, Stockholm, Sweden.

Evanno, G., Regnaut, S., Goudet, J., 2005. Detecting the number of clusters of individuals using the software Structure: a simulation study. Mol. Ecol. 14, 2611-2620.

Excoffier, L., Ray, N., 2008. Surfing during population expansions promotes genetic revolutions and structuration. Trends Ecol. Evol. 23, 347-351.

Falush, D., Stephens, M., Pritchard, J.K., 2003. Inference of population structure using multilocus genotype data linked loci and correlated allele frequencies. Genetics 164, 1567-1587.

Frankham, R., 1995. Effective population size/adult population size ratios in wildlife: a review. Genet. Res. 66, 95-107.

Frankham, R., 2005. Genetics and extinction. Biol. Conserv. 126, 131-140.

Garza, J.C., Williamson, E.G., 2001. Detection of reduction in population size using data from microsatellite loci. Mol. Ecol. 10, 305-318.

Goudet, J., 1995. FSTAT (version 1.2): a computer program to calculate F-statistics. J. Heredity 86, 485-486.

Habel, J.C., Ulrich, W., Assmann, T., Masters, J., 2013. Allele elimination recalculated: nested subset analyses for molecular biogeographical data. J. Biogeogr. 40, 769777.

Hamm, C.A., Aggarwal, D., Landis, D.A., 2010. Evaluating the impact of non-lethal DNA sampling on two butterflies, Vanessa cardui and Satyrodes eurydice. J. Insect Conserv. 14, 11-18.

Hardy, O.J., Vekemans, X., 2002. SPAGeDi: a versatile computer program to analyse spatial genetic structure at the individual or population levels. Mol. Ecol. Notes 2, 618-620.

Hardy, O.J., Charbonnel, N., Freville, H., Heuertz, M., 2003. Microsatellite allele sizes a simple test to assess their significance on genetic differentiation. Genetics 163, 1467-1482.

Hubisz, M.J., Falush, D., Stephens, M., Pritchard, J.K., 2009. Inferring weak population structure with the assistance of sample group information. Mol. Ecol. Res. 9, $1322-1332$.

IUCN, 1995. IUCN Guidelines on Re-introductions. IUCN, Gland.

IUCN, 2013. Guidelines for Re-introductions and other Conservation Translocations. IUCN, Gland.

Joyce, D.A., Pullin, A.S., 2003. Conservation implications of the distribution of genetic diversity at different scales: a case study using the marsh fritillary butterfly (Euphydryas aurinia). Biol. Conserv. 114, 453-461.

Klopfstein, S., Currat, M., Excoffier, L., 2006. The fate of mutations surfing on the wave of a range expansion. Mol. Biol. Evol. 23, 482-490.

Koscinski, D., Crawford, L.A., Keller, H.A., Keyghobadi, N., 2011. Effects of different methods of non-lethal tissue sampling on butterflies. Ecol. Entomol. 36, $301-$ 308.

Kudrna, O., Harpke, A., Lux, K., Pennerstorfer, J., Schweiger, O., Settele, J., Wiemers, M., 2011. Distributions Atlas of Butterflies in Europe. Gesellschaft für Schmetterlingsschutz, Halle, Germany. 
Lushai, G., Fjellsted, W., Marcovitch, O., Aagaard, K., Sherratt, T.N., Allen, J.A., Maclean, N., 2000. Application of molecular techniques to non-lethal tissue samples of endangered butterfly populations (Parnassiuss apollo L.) in Norway for conservation management. Biol. Conserv. 94, 43-50.

Mantel, N., 1967. Detection of disease clustering and a generalized regression approach. Cancer Res. 27, 209.

Merckx, T., Huertas, B., Basset, Y., Thomas, J.A., 2013. A global perspective on conserving butterflies and moths and their habitats. In: MacDonald, D., Willis, K. (Eds.), Key Topics in Conservation II. Wiley, London, pp. 239-257.

Oates, M.R., Warren, M.S., 1990. A Review of Butterfly Introductions in Britain and Ireland. World Wide Fund for Nature, Godalming.

Peakall, R., Smouse, P.E., 2012. GenAlEx 6.5: genetic analysis in Excel. Population genetic software for teaching and research - an update. Bioinformatics 28 , 2537-2539.

Pe'er, G., Settele, J., 2008. Butterflies in and for conservation: trends and prospects. Israel J. Ecol. Evol. 54, 7-17.

Peery, M.Z., Kirby, R., Reid, B.N., Stoelting, R., Doucet-Bëer, E., Robinson, S., VásquezCarrillo, C., Pauli, J.N., Palsbøll, P.J., 2012. Reliability of genetic bottleneck tests for detecting recent population declines. Mol. Ecol. 21, 3403-3418.

Phillippe, J., Lagoda, P.J.L., 1996. Microsatellites, from molecules to populations and back. Trends Ecol. Evol. 11, 424-429.

Phillips, B.L., Brown, G.P., Shine, R., 2010. Life-history evolution in range-shifting populations. Ecology 91, 1617-1627.

Pritchard, J.K., Stephens, M., Donnelly, P., 2000. Inference of population structure using multilocus genotype data. Genetics 155, 945-959.

Rousset, F., 1997. Genetic differentiation and estimation of gene flow from Fstatistics under isolation by distance. Genetics 145, 1219-1228.

Rousset, F., 2008. GENEPOP'007: a complete re-implementation of the GENEPOP software for Windows and Linux. Mol. Ecol. Res. 8, 103-106.

Roy, D.B., Rothery, P., Moss, D., Pollard, E., Thomas, J.A., 2001. Butterfly numbers and weather: predicting historical trends in abundance and the future effects of climate change. J. Anim. Ecol. 70, 201-217.

Rutkowski, R., Sielezniew, M., Szostak, A., 2009. Contrasting levels of polymorphism in cross-amplified microsatellites in two endangered xerothermophilous, obligatorily myrmecophilous, butterflies of the genus Phengaris (Maculinea) (Lepidoptera: Lycaenidae). Eur. J. Entomol. 106, 457-469.

Settele, J., Kühn, E., Thomas, J.A. (Eds.) 2005. Studies in the Ecology \& Conservation of Butterflies in Europe II. Species ecology along a European gradient: Maculinea butterflies as a model. Pensoft, Sofia.

Settele, J., Kühn, E., 2009. Insect conservation. Science 325, 41-42.

Sielezniew, M., Rutkowski, R., 2012. Population isolation rather than ecological variation explains the genetic structure of endangered myrmecophilous butterfly Phengaris (=Maculinea) arion. J. Insect Conserv. 16, 39-50.

Soulé, M.E., 1987. Viable Populations for Conservation. Cambridge University Press, Cambridge.

Tallmon, D.A., Koyuk, A., Luikart, G., Beaumont, M.A., 2008. ONeSAMP: a program to estimate effective population size using approximate Bayesian computation. Mol. Ecol. Res. 8, 299-301.

Thomas, J.A., 1980. Why did the Large Blue become extinct in Britain? Oryx 15, 243-247.
Thomas, J.A., 2005. Monitoring change in the abundance and distribution of insects using butterflies and other indicator groups. Phil. Trans. R. Soc. B 360, 339-357.

Thomas, J.A., 2010. Butterflies. In: McLean, N. (Ed.), Since Silent Spring. Cambridge University Press, Cambridge, pp. 430-447.

Thomas, J.A., Settele, J., 2004. Butterfly mimics of ants. Nature 432, 283-284.

Thomas, J., Simcox, D., Wardlaw, J., Elmes, G., Hochberg, M., Clarke, R., 1998. Effects of latitude, altitude and climate on the habitat and conservation of the endangered butterfly Maculinea arion and its Myrmica ant hosts. J. Insect Conserv. 2, 39-46.

Thomas, J.A., Telfer, M.G., Roy, D.B., Preston, C.D., Greenwood, J.J.D., Asher, J., Fox, R., Clarke, R.T., Lawton, J.H., 2004. Comparative losses of British butterflies, birds, and plants and the global extinction crisis. Science 303, 1879.

Thomas, J.A., Elmes, G.W., Schönrogge, K., Simcox, D.J., Settele, J., 2005b. Primary hosts, secondary hosts and 'non-hosts': common confusions in the interpretation of host specificity in Maculinea butterflies and other social parasites of ants. In: Settele, J., Kühn, E., Thomas, J.A. (Eds.), Studies on the Ecology and Conservation of Butterflies in Europe. Pensoft Publishers, SofiaMoscow, pp. 99-104.

Thomas, J.A., Simcox, D.J., Clarke, R.T., 2009. Successful conservation of a threatened Maculinea butterfly. Science 325, 80-83.

Thomas, J.A., Simcox, D.J., Hovestadt, T., 2011a. Evidence based conservation of butterflies. J. Insect Conserv. 15, 241-258.

Thomas, J.A., Simcox, D.J., Bourn, N.A.D., 2011b. Large blue butterfly in the UK. In: Soorae, P.S. (Ed.), IUCN, Gland, pp. 10-14.

Ugelvig, L.V., Nielsen, P.S., Boomsma, J.J., Nash, D.R., 2011. Reconstructing eight decades of genetic variation in an isolated Danish population of the large blue butterfly Maculinea arion. BMC Evol. Biol. 11.

Ugelvig, L.V., Andersen, A., Boomsma, J.J., Nash, D.R., 2012. Dispersal and gene flow in the rare, parasitic Large Blue butterfly Maculinea arion. Mol. Ecol. 21, 3224-3236.

Van Oosterhout, C., Hutchinson, W.F., Wills, D.P.M., Shipley, P., 2004. MICROCHECKER: software for identifying and correcting genotyping errors in microsatellite data. Mol. Ecol. Notes 4, 535-538.

van Swaay, C.A.M., Warren, M.S., 2006. Prime butterfly areas of Europe: an initial selection of priority sites for conservation. J. Insect Conserv. 10, 5-11.

van Swaay, C., Cuttelod, A., Collins, S., Maes, D., Munguira, M.L., Šašić, M., Settele, J., Verovnik, R., Verstrael, T., Warren, M., Wiemers, M., Wynhoff, I., 2010. European Red List of Butterflies. Publications Office of the European Union, Luxembourg.

Wallace, B., 1981. Basic Population Genetics. Columbia University Press, New York Guildford.

Wright, S., 1938. Size of population and breeding structure in relation to evolution. Science 87, 430-431.

Wynhoff, I., de Vos, H., van Zuijen, M.P., Prins, H.H.T., Brakefield, P.M., 2001. Genetic Variation Is Retained After Reintroduction of the Butterflies Maculinea Nausithous and Maculinea Teleius.in Wynhoff, I. At Home on Foreign Meadows the Reintroduction of Two Maculinea Butterfly Species. PhD Thesis. Wageningen University.

Zeisset, I., Als, T., Settele, J., Boomsma, J., 2005. Microsatellite markers for the larbge blue butterflies Maculinea nausithous and Maculinea alcon (Lepidoptera : Lycaenidae) and their amplification in other Maculinea species. Mol. Ecol. Notes 5, 165-168. 